Special issue of the 3rd International Conference on Computational and Experimental Science and Engineering (ICCESEN 2016)

\title{
Pack Siliconizing of Ti6Al4V Alloy
}

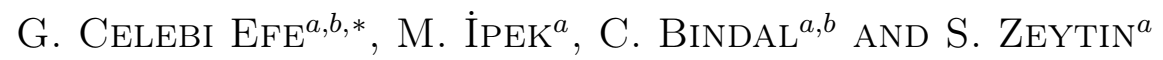 \\ ${ }^{a}$ Sakarya University, Engineering Faculty, Department of Metallurgy and Materials Engineering, \\ Esentepe Campus, 54187 Sakarya, Turkey \\ ${ }^{b}$ Sakarya University, Biomedical, Magnetic and Semi Conductive Materials Research Center (BIMAS-RC), Esentepe
}

\begin{abstract}
In this study, it was aimed to produce titanium silicide layer on Ti6Al4V by a simple, cheap and efficient method of pack siliconizing. Siliconizing was performed in a pack containing a mixture composed of $\mathrm{SiO}_{2}$ powder as siliconizing source, pure $\mathrm{Al}$ powder as a reducer for siliconizing, $\mathrm{NH}_{4} \mathrm{Cl}$ as an activator and $\mathrm{Al}_{2} \mathrm{O}_{3}$ powder as filler, at $1000^{\circ} \mathrm{C}$ for 8,10 and 12 hours in open atmospheric furnace. Optical microscope and SEM-EDS studies indicate that the morphology of silicide layers has smooth, dense and layered nature. The presence of phases, confirmed by XRD analyses, reveals that the silicide layers formed at $1000{ }^{\circ} \mathrm{C}$ are composed of $\mathrm{TiSi}_{2}, \mathrm{Ti}_{3} \mathrm{Si}_{5}, \mathrm{TiN}$, $\mathrm{TiO}_{2}$ and $\mathrm{SiO}_{2}$ compounds. Silicide layer thickness was increased with increasing process time and ranged from 7.5 to $9.0 \mu \mathrm{m}$. Hardness of silicide layers, measured by Vickers indentation, is over $2100 \mathrm{HV}$.
\end{abstract}

DOI: 10.12693 /APhysPolA.132.760

PACS/topics: 81.65.Lp, 81.65.-b

\section{Introduction}

Titanium and its alloys have superior properties, such as high strength, excellent corrosion resistance, low density, high specific strength, low modulus and good biocompatibility, making them interesting for many industrial applications, such as aeronautical, marine, power generation, chemical industries, sports and leisure transportation and biomedical devices $[1,2]$. However, excessive wear, erosion, friction and rapid oxidation of titanium surfaces limits their engineering applications, such as gears, shafts, axles, bearings, etc. [2,3]. The maximum application temperature of Ti6 Al4V alloy is below $350^{\circ} \mathrm{C}$ due to its poor high temperature oxidation [3]. The poor high-temperature oxidation resistance of $\mathrm{Ti}$ and its alloys may be attributed to the high solubility of $\mathrm{O}_{2}$ in Ti [4]. Thus Ti6Al4V alloy could only be used to produce fan blades and first and second blades of aircraft engines $[3,4]$.

In order to improve high temperature oxidation resistance of titanium alloys there are many surface modification methods [1-3]. Surface siliconizing, which produces hard silicide layers with excellent chemical resistance at high-temperatures, has been extensively studied for hightemperature automotive and aerospace applications [2]. Surface siliconizing also had an effect on the improvement of the oxidation resistance with the formation of $\mathrm{SiO}_{2}$ on the surface of the substrate [4]. Silicon atoms react with the surface of titanium and its alloys, reduce the depth and also diffusion rate of the oxygen penetration into the surface and the porosity of the scales. Pack siliconizing is the cheapest and the simplest method, consisting of embedding the sample into the siliconizing powder mixture and annealing under the vacuum [5].

*corresponding author; e-mail: gcelebi@sakarya.edu.tr
The main goal of the present research is to form titanium silicide compounds on the surface of Ti6Al4V alloy using $\mathrm{SiO}_{2}$ powder as depositing source, via pack siliconizing method at $1000^{\circ} \mathrm{C}$ for different times in open atmospheric furnace. Silica sand has some technical advantages, such as high specific strength, high specific hardness, high melting point, being more economical than pure $\mathrm{Si}$, providing an easy way to alter pack compositions [6] and hence can be used as source of silicon.

Silicide layer was characterized by various analytical methods, including optical microscopy, scanning electron microscopy (SEM), energy dispersion spectrometry (EDS), X-ray diffraction (XRD), microhardness profiling.

\section{Experimental}

Ti6Al4V alloy was used as substrate material for siliconizing. The samples of $5 \mathrm{~mm}$ in height were cut from annealed bars $10 \mathrm{~mm}$ in diameter. Sample surfaces were ground with $\mathrm{SiC}$ paper up to 1200 grit and polished with $1 \mu \mathrm{m} \mathrm{Al} \mathrm{Al}_{2} \mathrm{O}_{3}$ suspension. Surface cleaned samples were embedded in pack siliconizing powder mixture and filled with graphite powder. Pack siliconizing media mainly consist of $\mathrm{SiO}_{2}$, as siliconizing source, $\mathrm{NH}_{4} \mathrm{Cl}$, as activator, pure $\mathrm{Al}$, as reducer and $\mathrm{Al}_{2} \mathrm{O}_{3}$, as filler material.

Silica sand $\left(\mathrm{SiO}_{2}\right)$ was used as silicon source in this work. However, there is no published work related to the siliconizing of Ti6Al4V alloy substrate by using silica sand in open literature.

Siliconizing heat treatment was performed at $1000^{\circ} \mathrm{C}$ for 8,10 and $12 \mathrm{~h}$ in the open atmospheric furnace in an alumina crucible. Microstructure studies of siliconized samples were performed by using an optical microscope and SEM. The adequacy of silicide coatings was also verified by microhardness measurements. SEM-EDS analysis was performed to determine the components of the microstructure. The phases, formed on the surfaces of the coated samples, were identified with a Rigaku X-ray diffractometer, using the $\mathrm{Cu} K_{\alpha}$ radiation with a wavelength of $0.15418 \mathrm{~nm}$ over a $2 \theta$ range of $10^{\circ}$ to $90^{\circ}$. 


\section{Results and discussion}

Metallographic cross-sections of the silicide coatings were prepared using conventional metallographic polishing techniques and chemically etched with the solution of Keller. Optic microscope images of Ti6Al4V alloy siliconized at $1000{ }^{\circ} \mathrm{C}$ for 8,10 and 12 hours are given in Fig. 1. As it can be seen in Fig. 1, a white layer has formed beneath the coating layer due to heat treatment of titanium and its alloys, performed in open atmosphere absorbing oxygen and nitrogen on the surface of test material, which stabilize the alpha and form a hard, brittle layer referred to as alpha case [7].

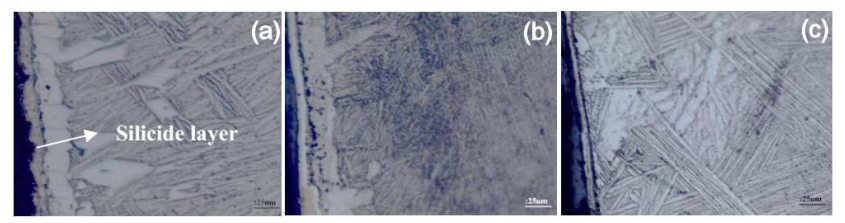

Fig. 1. Optical microstructures of Ti6Al4V alloy pack siliconized at $1000^{\circ} \mathrm{C}$ for (a) 8, (b) 10 and (c) 12 hours $(20 \times)$.

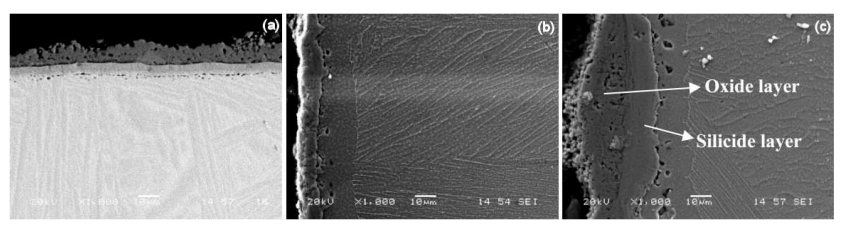

Fig. 2. SEM microstructures of Ti6Al4V alloy pack siliconized at $1000^{\circ} \mathrm{C}$ for (a) 8, (b) 10 and (c) 12 hours.

It was observed that silicide layer is thin, compact and is of white color. For further analysis of silicide layer, the SEM study was performed and SEM images are given in Fig. 2. Silicide coatings exhibit rough surface. It is seen that layer is composed of two sublayers, including an oxide layer on top, shown in Fig. 2c.
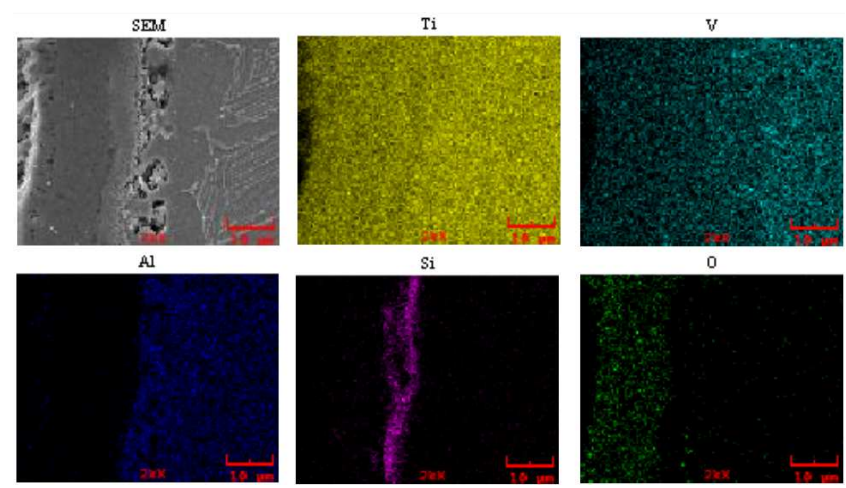

Fig. 3. SEM MAP analysis of Ti6Al4V alloy pack siliconized at $1000^{\circ} \mathrm{C}$ for 12 hours.

SEM-map images show that the outer layer contains $\mathrm{O}$ and $\mathrm{Ti}$, that is, there is an oxide layer over the silicide layer (Fig. 3). According to the results of EDS analysis, given in Table I, the coating layer consists of $\mathrm{Ti}, \mathrm{Si}$ and $\mathrm{N}$. Nitrogen in the coating layer is probably originating from the $\mathrm{NH}_{4} \mathrm{Cl}$, used as activator.

There is porosity between the coating layer and the matrix, originated from vapourizing of $\mathrm{Cl}$ gases, with increasing siliconizing time. Titanium alloys, in general, readily absorb oxygen, leading to oxidation when exposed to high temperatures $\left(>500^{\circ} \mathrm{C}\right)$, in air. In order for titanium alloys to be utilized more effectively at higher temperatures, the ingress of oxygen must be reduced, if not prevented completely [8]. In our study siliconizing heat treatment was performed in open atmosphere and so, probably the oxides, formed on the surface of samples before siliconizing, had caused the formation of porosity. In order to avoid these oxides and gas vacancies, siliconising heat treatment must be done in vacuum or controlled atmosphere.

TABLE I

SEM EDS analysis of Ti6Al4V alloy pack siliconized at $1000^{\circ} \mathrm{C}$ for $10 \mathrm{~h}$.
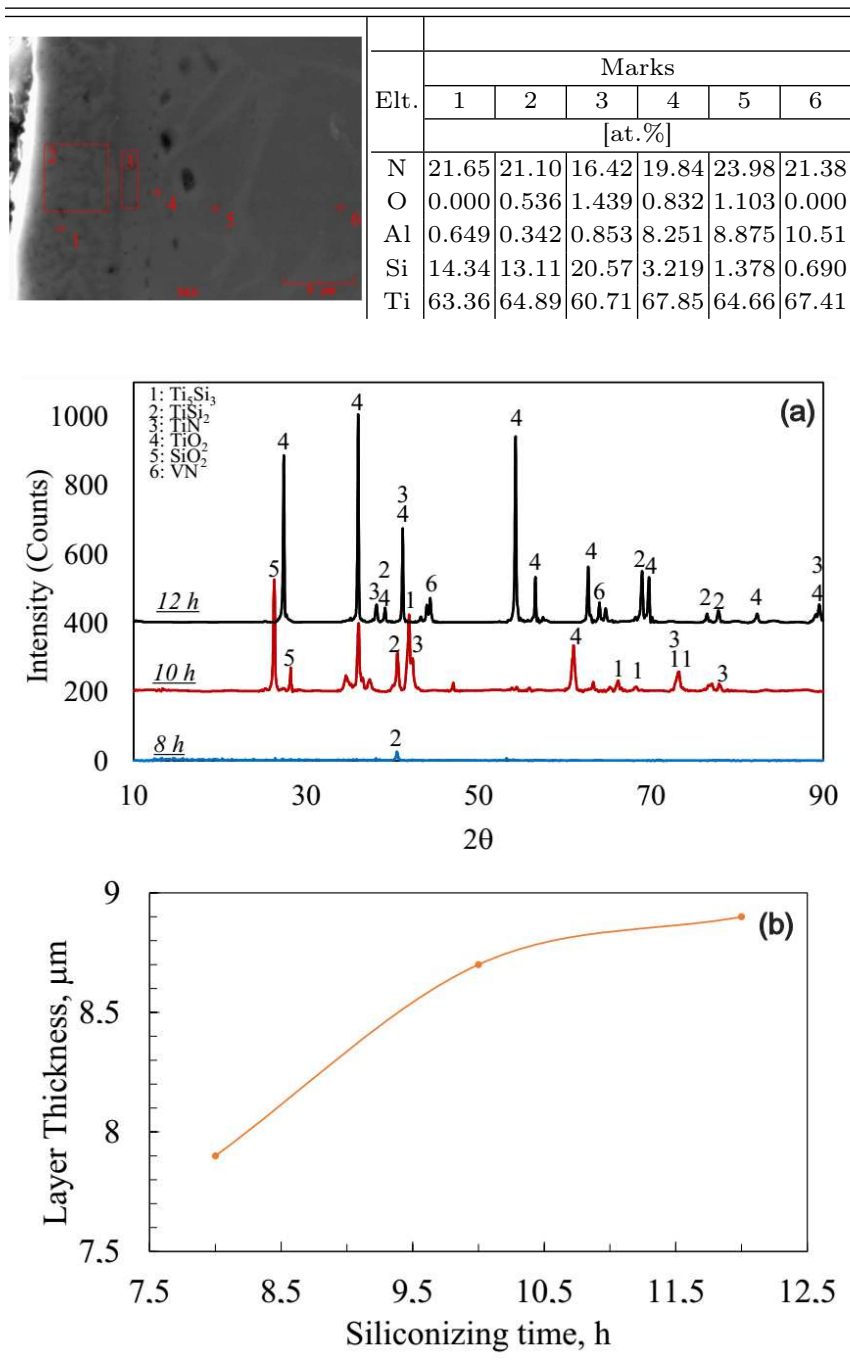

Fig. 4. (a) XRD analysis of Ti6Al4V alloy pack siliconized at $1000^{\circ} \mathrm{C}$ for 8,10 and 12 hours. (b) Variation of silicide layer thickness versus siliconizing time. 
XRD analysis studies indicate that dominant phases formed in the coating layer are $\mathrm{Ti}_{5} \mathrm{Si}_{3}, \mathrm{TiSi}_{2}, \mathrm{TiN}, \mathrm{TiO}_{2}$ and $\mathrm{SiO}_{2}$ (Fig. 4a). Ti/Si oxide on the coating surface prevents the diffusion of the $\mathrm{O}$ towards the matrix [4]. Intensity of all peaks has increased and in addition TiN and $\mathrm{VN}$ phases were detected with increasing siliconizing time.

The thickness and the composition of the surface layer, that develops during the siliconizing process, are affected by the type of the chemical reactions occurring at the sample surface, by the diffusivity of silicon in the treated material, by the process temperature and the time [9]. Thickness of silicide layer as a function of siliconizing time was measured by SEM and is given in Fig. 4b. Obtained results indicate, that silicide layer thickness had increased with increasing siliconizing time, however the rate of change was decreasing, especially for 12 hours siliconizing time. Measured thicknesses changes between 7.5 and $9 \mu \mathrm{m}$.

(a)
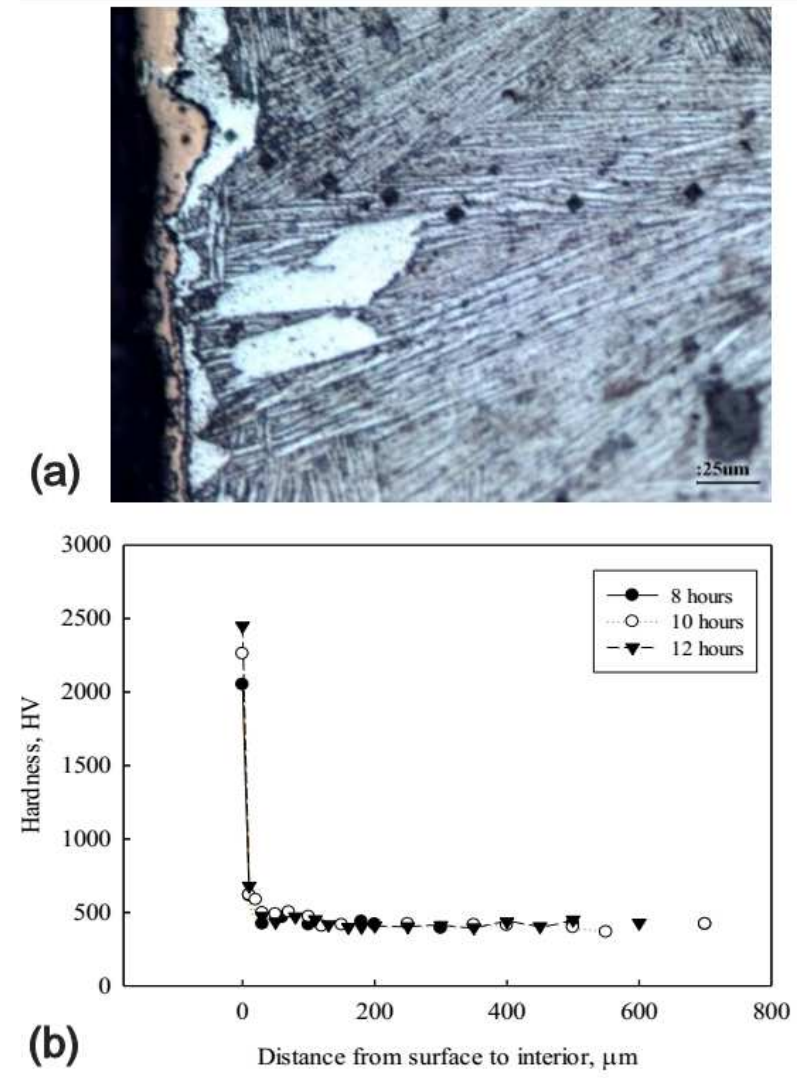

Fig. 5. (a) Optical microstructure of hardness tracks from surface to the interior of Ti6Al4V alloy pack siliconized at $1000^{\circ} \mathrm{C}$ for 10 hours. (b) Hardness results of Ti6Al4V alloy pack siliconized at $1000^{\circ} \mathrm{C}$ for 8,10 and 12 hours.
As it can be seen from Fig. 5, silicon diffusing into the substrate, leads to its hardening, which probably causes increasing wear resistance. Minimum surface hardness was over $2000 \mathrm{HV}$ and increased to $2480 \mathrm{HV}$ with increasing siliconizing time. Such high hardness is expected to be favorable for wear-resistance applications [10]. This high hardness can be attributed to fine-silicide precipitates present in the structure and also to nitride phases detected by XRD analysis.

\section{Conclusions}

The results presented in this work show that pack siliconizing is a perspective method for improving the surface properties of Ti6Al4V alloy. Homogeneous and dense compact layer composed of Ti-Si intermetalics, such as $\mathrm{Ti}_{5} \mathrm{Si}_{3}, \mathrm{TiSi}_{2}$ and also TiN and VN, was detected. The thickness of silicide layer has ranged from 7.5 to $9 \mu \mathrm{m}$ with increasing process time. Hardness of coatings has increased with increasing the siliconizing time. The minimum hardness of coating is six times higher than that of substrate $(350 \mathrm{HV})$. This is attributed to formation of the Ti-Si and Ti-N intermetallic coatings during the pack siliconizing. Some porosities were detected between compound layer and the substrate. To have a cleaner and porosity free compounds, pack siliconizing of $\mathrm{Ti}$ and its alloys should be performed in vacuum and in controlled atmosphere.

\section{References}

[1] C. Jian-Min, G. Chun, Z. Jian-Song, Trans. Nonferrous Met. Soc. China 22, 2171 (2012).

[2] D. Vojtech, P. Novak, P. Machac, M. Mortanikova, K. Jurek, J. Alloys Compounds 464, 179 (2008).

[3] S. Gugel, Heat Treating Progress May/June, 33 (2009).

[4] H. Xiong, W. Mao, W. Li Ma, Y. Xie, Y. Chen, H. Yuan, X. Li, Mater. Sci. Eng. A 433, 108 (2006).

[5] D. Vojtech, T. Kubatik, H. Cizoca, Mater. Sci. Forum 482, 243 (2005).

[6] M. Othman, F.M. Yusnenti, I. Mohd Yusri, Procedia CIRP 26, 554 (2015).

[7] G.F. Vander Voort, ASM Handbook, Volume 9: Metallography and Microstructures, ASM International, 2004, p. 899.

[8] I. Gurrappa, A.K. Gogia, Surf. Coat. Technol. 139 216 (2001).

[9] N. Syla, F. Aliaj, B. Dalipi, Acta Phys. Pol. A 130, 83 (2016).

[10] A. Günen, Acta Phys. Pol. A 130, 217 (2016). 